\title{
Game among Mobile Operators, Bank and the Third-party Payment Services Provider in Mobile Payment Market
}

\author{
Miao Miao, Fangping Xiong and Jing Zhou \\ School of Economics and Management, Southwest Jiaotong University \\ miaomiao@swjtu.edu.cn,fangpingxiong@126.com,xjmzj@126.com
}

\begin{abstract}
With the rapid development of mobile Internet and mobile payment market, mobile payment business has become the key of mobile value-added business. In order to maximize profits, the major players in the mobile payment market have been carrying on an intensive competition to grab market share. This paper analyzes from mobile operators, banks, and third-party payment services providers' perspective, combining with practical situation to build mobile payment market Cournot model with the complete information and the mobile payment market Cournot model with incomplete information, By solving and analyzing models, we propose a operational model for mobile payment market based on China's current situation which combines the joint collaboration by mobile operators and banks, as well as the support from the third-party payment services providers.
\end{abstract}

Keywords: Cournot Model, Bank, Mobile Operator, Third-party payment services provider

\section{Introduction}

Mobile payment is to allow users to use their mobile devices to consume goods or services as a way to pay the bill. Mobile devices including mobile phones, PDA, mobile PC etc., currently mobile phones are the most widely used mobile devices in mobile payment market, the payment charged from the mobile account through the mobile commonly referred to mobile payments [1]. September 5, 2011, the world's leading mobile Internet consulting agency iiMedia Research issued "China's mobile payment market development in the first half 2011 research report", which shows that the global mobile payment market is expanding, mobile payment market will grow from 380 billion dollars in 2011 to 600 billion dollars in 2013. In China, mobile payment market scale exceeded 100 billion yuan in 2010, and the market will reach 239.6 billion yuan. in 2013 While China Academy of Telecommunication Research (CATR) and China Mobile research projections indicate that in 2013 the total size of China's mobile payment industrial chain will exceed 150 billion yuan, and will maintain an annual growth rate of about 40 percent in the coming years. At present, the number of mobile phone users is growing and will maintain an increasing trend. The iiMedia Research data show that in 2013 the number of mobile phone users will be more than 1 billion people, and the growth rate of mobile phone users will maintain an upward trend in 2013 (as Figure 1 shown). The large scale of Chinese mobile phone users indicates that China's mobile payment market has bright prospects for development in the future. As mobile phone users keep increasing in China, the scale of mobile payment market is continuing to expand. As iiMedia Research consulting report showed, China's mobile payment users will grow from 100 million in 2010 to 200 million in 2011 , and in 2013 the user number will reach 400 million (Figure 2 ). The increasing numbers of mobile phone users and the expanding scale of mobile payment activities indicate a strong development potential for China mobile payment market. However, 
China's developing mobile payment market is still in a fledging period, facing huge competition and challenges, such as the mobile payment industrial chain is not mature enough, and the operation model of mobile payment market is not clear.

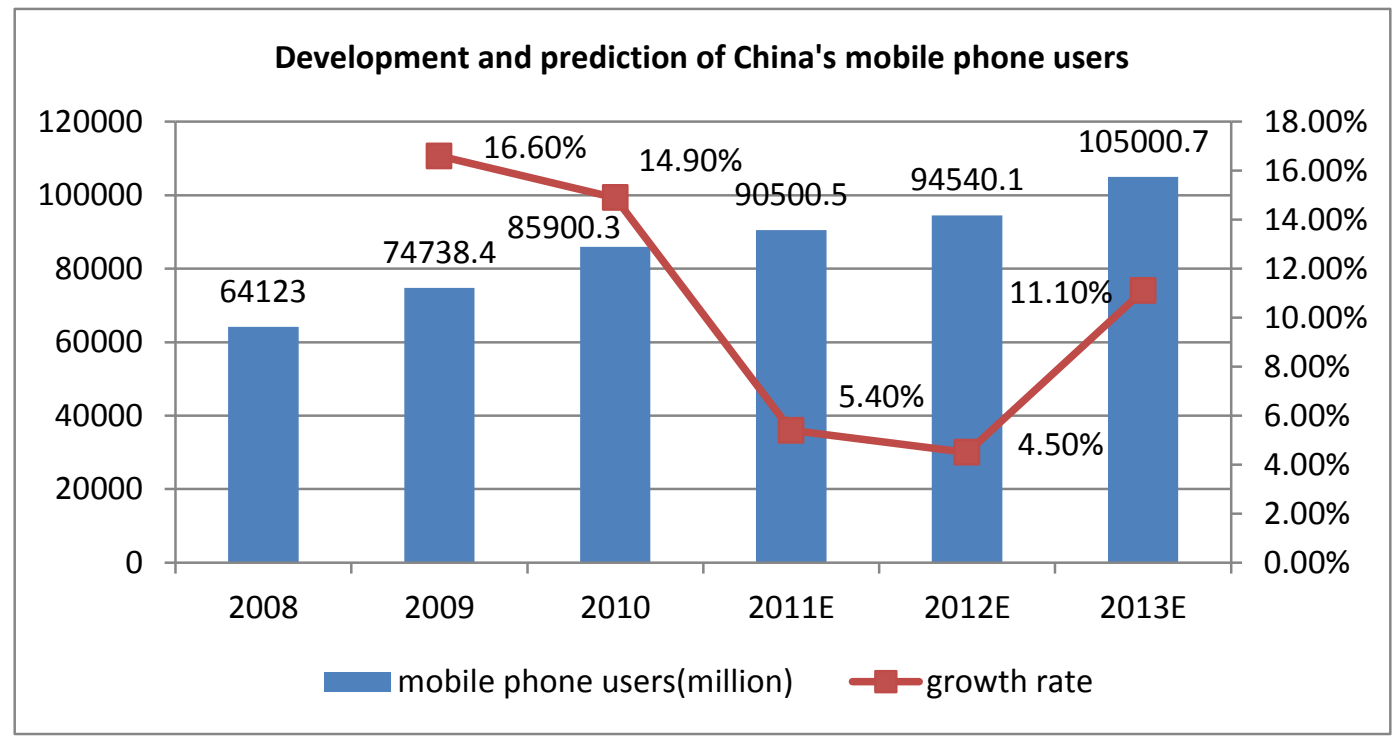

Figure 1. Development and Prediction of China's Mobile Phone users from 2008 to 2013

(Data Source: iiMedia Research, http://labs.chinamobile.com/news/53905)

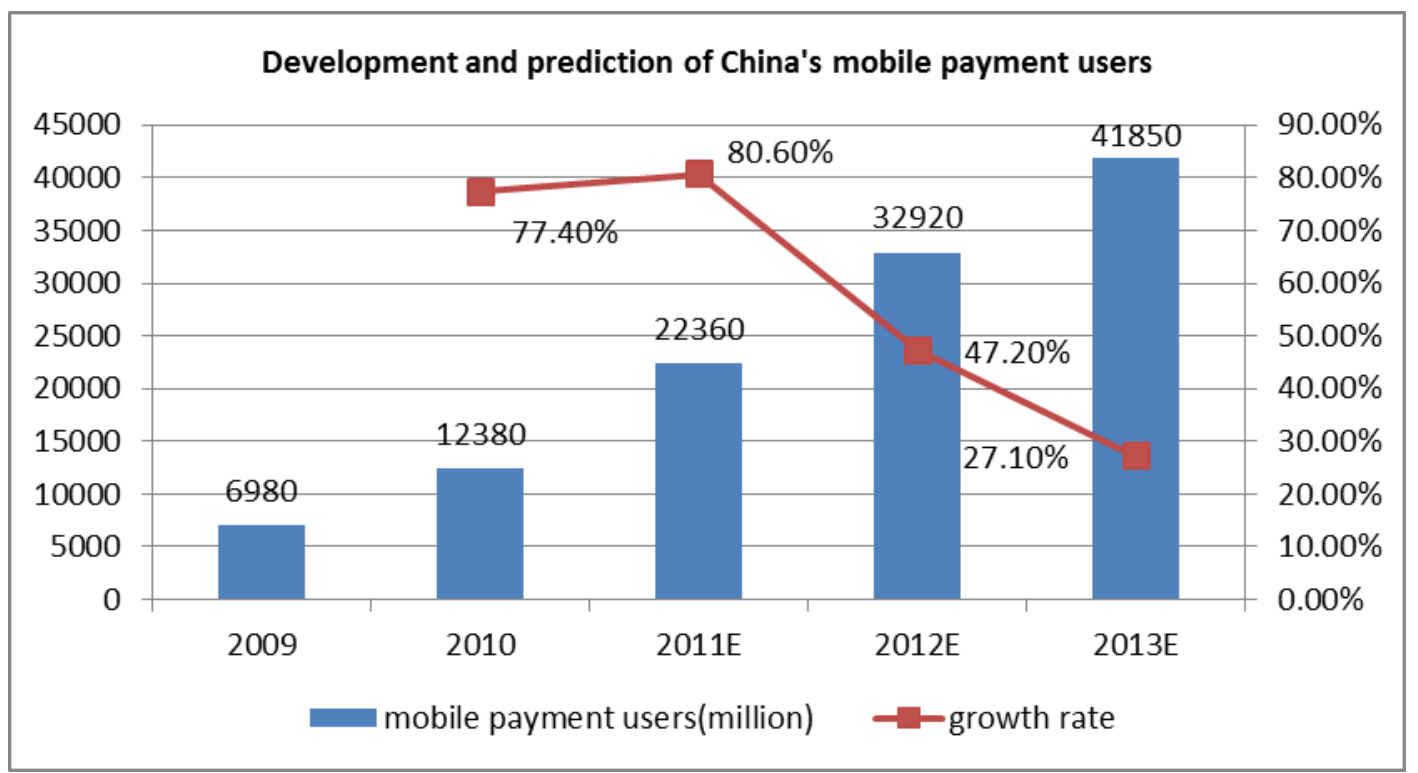

Figure 2. Development and Prediction of China's Mobile Payment Users from 2009 to 2013

(Data Source: iiMedia Research, http://www.iimedia.cn/16774.html)

In the mobile payment market, there are many participants among the mobile payment industrial chain, including mobile operators, financial institutions, third-party payment service 
providers, content providers, chip makers, mobile phone manufacturers, equipment providers, customer, and businesses etc. Mobile operator is responsible for building mobile payment platform and providing secure communication channels for mobile payments. Financial institution is responsible for managing the bank account which is associated with the user's mobile phone, and builds mobile payment platforms with complete and flexible security system, to ensure users' payment process goes smoothly and safely. Third-party payment service provider is responsible for integrating and coordinating various resources such as mobile operators and banks, to provide various mobile payment services for mobile phone users, and to attract users to consume for the applications. Mobile terminal and equipment providers provide mobile payment devices for the mobile payment service providers (including mobile operators, financial institutions, third-party payment service providers). Businesses and users are the mobile payment services users. The core organizers of the mobile payment industrial chain are mobile operators, financial institutions and third-party mobile payment service providers, of which the main mobile operators including China Mobile, China Unicom and China Telecom; financial institutions mainly refers to banks; and the third-party mobile payment Internet service provider mainly refers to the major such as Alipay, Tenpay, and 99Bill etc.

In other countries, the development of mobile payment is shown as Table 1, in which Japan and South Korea are the first countries to carry out mobile payment services and have the well developed markets. In terms of the operation model, Japan's mobile payment services operation model is the mobile operator-oriented mode. Japanese leading mobile operator NTTdocomo dominates the mobile payment industrial chain, which has adopted a cooperative operation model to collaborate with financial institutions, and kept improving its financial risk tolerance, breaking through the bottleneck of minimum payment scale and eliminating user's concerns towards payment security. South Korea, on the other hand, has adopted a bank-oriented operation model. However, Japan and Korea's successful application of mobile payment market operation model may not be suitable for China's market, we should explore and develop an operation model based on our own situation.

Table 1. Global Mobile Payment Development Classification

\begin{tabular}{l|l|l}
\hline \multicolumn{1}{c|}{ Country } & Development Stage & \multicolumn{1}{c}{ Development Situation } \\
\hline $\begin{array}{l}\text { Japan, Korea, } \\
\text { Philippines, } \\
\text { Singapore }\end{array}$ & Well developed & $\begin{array}{l}\text { Relatively mature operation models and industry } \\
\text { chain; good consumer consumption habits; } \\
\text { stable-developing market }\end{array}$ \\
\hline $\begin{array}{l}\text { Spain, Italy, } \\
\text { Sweden, } \\
\text { Finland }\end{array}$ & Rapidly developing & $\begin{array}{l}\text { operation model has been formed; the industrial } \\
\text { chain has gained a certain scale; business scope } \\
\text { needs to be expanded }\end{array}$ \\
\hline $\begin{array}{l}\text { France, United } \\
\text { Kingdom, } \\
\text { Germany, } \\
\text { United States }\end{array}$ & Less developed & $\begin{array}{l}\text { operation model is not clear; industry chain is not } \\
\text { perfect; technical standards and business forms are } \\
\text { in basic form; consumer consumption habits need to } \\
\text { be cultured }\end{array}$ \\
\hline
\end{tabular}

\section{Literature Review}

The current study suggests that mobile payment operation model has the following three categories: mobile operator-oriented, bank-oriented, third-party payment company-oriented, especially the first two models are mostly accepted. However, the views on which model will be successful in China are very different [2-13]. Zhang Anwei et al. analyze and compare the three dominant operation models in mobile payment industrial chain, which are financial 
institution-oriented model, mobile operator-oriented model and third-party payment company-oriented model. The analysis shows both advantages and disadvantages existing in the three models of operation, and the features of each model are quite obvious. In terms of the three dominant force for future development prospects, they think the financial institutions and mobile operators will gain a dominant position in the mobile payment industry chain, and third-party payment companies will also play an important role in the industrial chain, but they do not explicitly point out which model will dominate the future mobile payment market [2]. Huang Rongzhi suggests our country's mobile payment is still in the early stage of development. Since the industry chain is not mature, the operation model is not clear, and the benefits distribution and the mastership issues become the bottleneck of the development of mobile payments, the future prospects is not very clear, thus it is hard to predict China's mobile payment operation model [3]. Jiang Yong establishes the game model for four different cases between the mobile operator and financial institution, analyzing the development of mobile payment industrial chain and proposing possible suggestions, but he does not mention and predict China's mobile payment business development model [4]. Song Ying et al., develop the following five indicators which including credit rating, business richness, business promotion speed, interoperability, and payment amount to evaluate mobile payment operation model. The results show that the operator-oriented mode is superior to the other operation model, thus proposed the mobile operator-oriented mode is currently the mainstream operation model [5]. Zhou Huifeng analyzes from the perspectives of user scope, operation management ability and financial capacity etc., and suggests that telecom operators face more opportunities than challenges, and also he predicts that the mobile operator-oriented mobile payment model will become the mainstream operation model [6]. $\mathrm{Hu}$ Jun considers that the development of mobile payment services involve many stakeholders, so it is difficult to have only one model fit the market, all parties need to work together. Thus $\mathrm{Hu}$ suggests operators and financial institutions working together to build a third-party payment platform operation model would fit our country's situation [7]. Gu haiying et al., analyze the profit prospects of different models by profit model testing, they also hold the opinion that as the mobile payment industrial chain is a huge and complete industry chain, there will not be a single model dominating the market, it requires financial institutions, mobile operators and third-party payment companies collaborating with each other to make a profit [8]. Recently, Zhang Chunyan establish mobile Payment Market equilibrium quantitative models with game theory, the research find the game between Mobile operators and bank card companies is a long term environmental changes with the industrial Process, both competitive or cooperation strategy significantly lie on the initial state of the system. Under the assumption both of them have to Pay the high cost of switching Platforms, the cooperation will become the mainstream way [9]. Wei Guoqiang analyzes the three key mode of mobile payment with SWOT, and proposes evaluation criterion and problems of mobile payment base on SWOT, finally he proposes the model of mobile payment is dominated by mobile operators [10]. Most of the qualitative analysis above was general discussion, they did not combine China's mobile operators, banks and third-party payment unique characteristics to evaluate different operation models. Current research on third-party payments concentrated in the non-mobile Internet field. The third-party payment transaction model is considered gradually encroaching on the profits of banks in the market, whose development will inevitably be squeezed by banks [11-14]. The game between operators and banks in mobile payment market also did not discuss third-party payment companies [4, 13]. In addition, there are many uncertainties in mobile payment industry chain, such as regulatory policy, technology models, service models and operation models, any change in the factors is likely to lead a change in the collaborative model [15]. 
The study above did not consider the game between operators, banks and third-party payment companies participating at the same time, nor consider the third-party payment company as a buffer role between banks and operators. These studies are based on the general characteristics of the industry, and did not take Chinese companies' own characteristics into analysis. This paper aims to build an oligopoly game model between three major participants in China's mobile payment market, which include mobile operators, banks and third-party payment service providers. The paper intends to propose an operation model based on China's market situation, thus provides the operation model reference for China's mobile payment market.

\section{Modeling}

The Cournot model was posited by French economist Cournot in 1838, it is the early oligopoly model, which often used as a starting point for the analysis of oligopoly theory. The duopoly model is a relatively simple application of the Cournot model. The conclusions of the Cournot model can be extended to apply on three or more oligopoly firms cases [16]. The Cournot model as the main analyzing tool has been applied to the research on oligopoly firm game model in many areas, however, there is no researcher uses the Cournot model to analyze Chinese mobile payment market related issues. Mobile operators, banks and third-party payment service providers as the major participants in the highly competitive mobile payment market are striving to become the market leader in order to maximize the benefits. Mobile operators, banks, and third-party payment service providers can be seen as the oligopoly firms in the mobile payment market, there is an obvious game relationship between the three parties. According to the definition of 'industry', industry refers to a commodity market with the production and supply of goods of all firms in general [17], which indicates that the mobile operators, banks, and third-party payment service providers to provide mobile payment products belong to the same mobile payment products industry. Thus, this case can apply the Cournot Model. This paper will analyze from the perspectives of mobile operators, banks and third-party payment service providers, and build the Cournot oligopoly model with complete information and Cournot oligopoly model with incomplete information between these three oligopolies. By analyzing and comparing the mobile payment service provide capacity and revenue of operators, banks and third-party service providers in various conditions, we attempt to propose a operation model that is in line with our country's mobile payment market.

China's mobile payment market can be seen as an oligopoly market, so we build mobile operators, banks and third-party payment service providers as three Cournot oligopoly model to analyze the mobile payment market operation mode.

\subsection{Complete Information Cournot Model}

To build the three-oligopoly Cournot model of mobile operators, banks and third-party payment service providers, the model assumptions are:

(1) The mobile service providers in mobile payment market are mobile operators, banks and third-party payment service providers. Set q1 as the business volume of mobile payment service provided by mobile operators; set q2 as the business volume of mobile payment service provided by banks; set q3 as the business volume of mobile payment service provided by third-party payment service providers. So the total business volume of mobile payment service on the market is $Q=q_{1}+q_{2}+q_{3}$.

(2)The inverse demand curve function of mobile payment service on the market is 
$P=a-b Q(\mathrm{a}>0, \mathrm{~b}>0)$.

(3) Set the marginal cost of mobile operators, banks and third-party payment service provders as $\mathrm{c}_{1}, \mathrm{c}_{2}$ and $\mathrm{c}_{3}$ respectively. Fixed cost is $\mathrm{FC}=0$.

(4) The mobile payment services provided by mobile operators, banks and third-party payment service provider are homogeneous.

(5) Mobile operators, banks and third-party payment service providers are all based on the principle of maximizing their own interests.

(6) The information of mobile operators, banks and third-party payment service provider are fully understand by each other, each party can obtain complete information.

The payoff of each participant in the game is their individual profits in the mobile payment market. The profit functions of mobile operators, banks and third-party payment service providers are as below:

$$
\begin{aligned}
& \pi_{1}=\left[a-b\left(q_{1}+q_{2}+q_{3}\right)\right] q_{1}-c_{1} q_{1} \\
& \pi_{2}=\left[a-b\left(q_{1}+q_{2}+q_{3}\right)\right] q_{2}-c_{2} q_{2} \\
& \pi_{3}=\left[a-b\left(q_{1}+q_{2}+q_{3}\right)\right] q_{3}-c_{3} q_{3}
\end{aligned}
$$

According to the definition, Nash equilibrium is the strategy profiles of the best countermeasure strategies from players in the game ${ }^{[17]}$. Based on the Nash equilibrium conditions, the optimal solutions are shown below:

$$
\begin{aligned}
& \max \left\{\left[a-b\left(q_{1}+q_{2}+q_{3}\right)\right] q_{1}-c_{1} q_{1}\right\} \\
& \max \left\{\left[a-b\left(q_{1}+q_{2}+q_{3}\right)\right] q_{2}-c_{2} q_{2}\right\} \\
& \max \left\{\left[a-b\left(q_{1}+q_{2}+q_{3}\right)\right] q_{3}-c_{3} q_{3}\right\}
\end{aligned}
$$

Take the partial derivatives of profit function to get the maximum profit:

$$
\begin{aligned}
& \frac{\partial \pi_{1}}{\partial q_{1}}=0 ; \frac{\partial \pi_{2}}{\partial q_{2}}=0 ; \frac{\partial \pi_{3}}{\partial q_{3}}=0 . \text { Solving these three equations, we got: } \\
& q_{1}=\frac{a+c_{2}+\mathrm{c}_{3}-3 \mathrm{c}_{1}}{4 b} \\
& q_{2}=\frac{a+c_{1}+\mathrm{c}_{3}-3 \mathrm{c}_{2}}{4 b} \\
& q_{3}=\frac{a+c_{1}+\mathrm{c}_{2}-3 \mathrm{c}_{3}}{4 b}
\end{aligned}
$$

The solutions of Nash equilibrium in the mobile payment market Cournot model are q1,q2 and q3. Substituting q1,q2,q3 into functions (1)(2)(3) can get the profits of mobile operator $\pi_{1}$, the profits of banks $\pi_{2}$, and the profits of third-party payment service providers $\pi_{3}$ : 


$$
\pi_{1}=\frac{\left(a+c_{2}+c_{3}-3 c_{1}\right)^{2}}{16 b}, \pi_{2}=\frac{\left(a+c_{1}+c_{3}-3 c_{2}\right)^{2}}{16 b}, \pi_{3}=\frac{\left(a+c_{1}+c_{2}-3 c_{3}\right)^{2}}{16 b}
$$

\subsection{Incomplete Information Cournot Model}

Complete information on the condition is an ideal state, which generally applies only to analyze the ideal state. However, this ideal state does not exist in the reality. So we build the Cournot model with incomplete information for the general case in the mobile payment market on the assumption that:

(1) The three parties in the mobile payment market to provide mobile payment services are: mobile operators, banks and third-party payment service providers. $\mathrm{q}_{1}$ represents the business volume of mobile operators, $\mathrm{q}_{2}$ represents the business volume of banks, and $\mathrm{q}_{3}$ represents the business volume of third-party payment service providers. The total business volume of mobile payment service in the market is $Q=q_{1}+q_{2}+q_{3}$

(2) The inverse demand function of mobile payment service in the market is $P=a-b Q(\mathrm{a}>0, \mathrm{~b}>0)$.

(3) The cost of mobile operator is $c_{1}$, while $c_{1}^{L}$ represents the low cost of mobile operator, $c_{1}^{H} \quad$ represents the high cost of mobile operator. The mobile operator knows exactly which kind of cost for itself, but the bank and the third-party payment service provider are not clear about the cost of mobile operator, so banks and third-party payment service providers obtain the incomplete information.

(4) Banks and third-party payment service providers obtain the incomplete information, thus the probability of banks and third-party payment service providers knowing the cost of mobile operators as $c_{1}{ }_{1}$ and $c_{1}{ }^{H}$ are $\mathrm{P}\left(c_{1}=c_{1}{ }^{L}\right)=1-\theta, \mathrm{P}\left(c_{1}=c_{1}{ }^{H}\right)=\theta$

(5) The mobile payment services provided by mobile operators, banks and third-party payment service providers are homogeneous, and all of them are based on the principle of profit maximization.

Building Cournot model with incomplete information for mobile operators, banks and third-party payment service providers, and solve the model, the process is as the following.

The profit function of the mobile operator is:

$$
\pi_{1}=\left[a-b\left(q_{1}+q_{2}+q_{3}\right)\right] q_{1}-c_{1} q_{1}, \text { to meet the condition for profit maximization, we }
$$

set $\frac{\partial \pi_{1}}{\partial q_{1}}=0$, the solution is $q_{1}=\frac{a-c_{1}-b q_{2}-b q_{3}}{2 b}$.

When $c_{1}=c_{1}^{L}$, the business volume of the mobile operator is:

$$
q_{1}^{H}=\frac{a-c_{1}^{L}-b q_{2}-b q_{3}}{2 b}
$$

When $c_{1}=c_{1}^{H}$, the business volume of the mobile operator is:

$$
q_{1}^{L}=\frac{a-c_{1}^{H}-b q_{2}-b q_{3}}{2 b}
$$

The profit function of the bank is: 


$$
\pi_{2}=(1-\theta) q_{2}\left[a-b\left(q_{1}^{H}+q_{2}+q_{3}\right)-c_{2}\right]+\theta q_{2}\left[a-b\left(q_{1}^{L}+q_{2}+q_{3}\right)-c_{2}\right], \text { proposing }
$$

to meet the condition of profit maximization, set $\frac{\partial \pi_{2}}{\partial q_{2}}=0$, we got:

$$
q_{2}=\frac{a-c_{2}-b q_{3}-(1-\theta) b q_{1}^{H}-\theta b q_{1}^{L}}{2 b}
$$

The profit function of the third-party payment service provider is:

$$
\pi_{3}=(1-\theta) q_{3}\left[a-b\left(q_{1}^{H}+q_{2}+q_{3}\right)-c_{3}\right]+\theta q_{3}\left[a-b\left(q_{1}^{L}+q_{2}+q_{3}\right)-c_{3}\right] \text {, proposing }
$$

to meet a condition of profit maximization, set $\frac{\partial \pi_{3}}{\partial q_{3}}=0$, we got:

$$
q_{3}=\frac{a-c_{3}-b q_{2}-(1-\theta) b q_{1}^{H}-\theta b q_{1}^{L}}{2 b}
$$

To derive the solution of Nash equilibrium, we solve simultaneous equations (1)(2)(4)

$$
\begin{aligned}
& q_{2}=\frac{a+c_{3}-3 c_{2}+(1-\theta) c_{1}^{L}+\theta c_{1}^{H}}{4 b} \\
& q_{3}=\frac{a+c_{2}-3 c_{3}+(1-\theta) c_{1}^{L}+\theta c_{1}^{H}}{4 b} \\
& q_{1}^{H}=\frac{a+c_{3}+c_{2}-(3-\theta) c_{1}^{L}-\theta c_{1}^{H}}{4 b} \\
& q_{1}^{L}=\frac{a+c_{3}+c_{2}-(1-\theta) c_{1}^{L}-(2+\theta) c_{1}^{H}}{4 b}
\end{aligned}
$$

\subsection{Cooperation Model}

The complete information Cournot model and incomplete information Cournot model above indicate that all the participants in the mobile payment market are all aiming to maximum their own profits instead of collaborating with each other. Assuming mobile operators, banks and third-party payment service providers collaborate with each other, which will be equivalent as one monopoly mobile service provider that combined by the three parties. The assumptions of cooperation model is the same as Cournot model with complete information, thus the total profits will be:

$$
\begin{aligned}
& \pi_{h}=P(Q) Q-C Q, \text { to maximize the total profit, set } \frac{\partial \pi_{h}}{\partial Q}=0, \text { we got: } \\
& Q=\frac{a-c}{2 b}, \text { substitute } Q \text { into } \pi_{h}=P(Q) Q-C Q, \text { we got the total profits of three parties }
\end{aligned}
$$

under the cooperation model: $\pi_{h}=\frac{(a-c)^{2}}{4 b}$. 


\section{Equilibrium Analysis of Game Model}

(1) In the complete information Cournot model, the business volume of the mobile payment service provided by mobile operators, banks, and the third-party service providers are represented as the following: $q_{1}=\frac{a+c_{2}+\mathrm{c}_{3}-3 \mathrm{c}_{1}}{4 b} ; \quad q_{2}=\frac{a+c_{1}+\mathrm{c}_{3}-3 \mathrm{c}_{2}}{4 b}$; $q_{3}=\frac{a+c_{1}+\mathrm{c}_{2}-3 \mathrm{c}_{3}}{4 b}$. Mobile operators, banks, and the third-party service providers all pursue to maximize their own profits. Thus, the competition between the three parties making all three have the same business scale and competitive strength, which makes the marginal cost of the mobile payment service of three parties are equal. Set $c_{1}=c_{2}=c_{3}=c$, then $q_{1}=q_{2}=q_{3}=\frac{a-c}{4 b}$, The total business volume of mobile payment service in the mobile payment market is: $Q=q_{1}+q_{2}+q_{3}=\frac{3(a-c)}{4 b}$, the total profit of all these three service providers is $\pi=\frac{3(a-c)^{2}}{16 b}$. When mobile operators, banks, and the third-party service providers cooperate with each other, the total business volume of mobile payment service is $Q_{h}=\frac{a-c}{2 b}$, the total profit is $\pi_{h}=\frac{(a-c)^{2}}{4 b}$.

In the complete information Cournot model, each party in the market makes decision independently and pursues their individual profits instead of collaborating with each other in the cooperation model. Comparing the business volume and total profits of the complete information Cournot model and the cooperation model, we got: $Q=\frac{3(a-c)}{4 b}>Q_{h}=\frac{a-c}{2 b}$, and $\pi=\frac{3(a-c)^{2}}{16 b}<\pi_{h}=\frac{(a-c)^{2}}{4 b}$, When applying the cooperation model, we can find that the overall business volume is small, but the total profits are high. So if mobile operators, banks and third-party payment service providers can cooperate to decide the volume of services in the market, then the scale effect can be achieved. Thus, the three parties can complement each other's advantages and optimiz their resources, meanwhile reduce unnecessary investment links and increase productivity, thus to reduce costs, improve gross profit, and increase social welfare.

(2) The Nash equilibrium combination in the complete information Cournot model fails to make every participants in the mobile payment market to achieve the maximum profit, instead, it becomes the "prisoner's dilemma" between mobile operators, banks and third-party payment service providers. However, the business volume provided by each service provider is not easy to achieve in this model, each party has the motives to deviate from this cooperation model. Because when mobile operators, banks and third-party payment service providers cooperating to form a monopoly, the corresponding market price is relatively high, while the production is relatively low. In this case, driving by the temptation of high price, each party intends to increase production in order to get higher profits. Thus, there is a need to require the government policies and regulations, or service protocols to stabilize the market. Otherwise such low yields high-profit status cooperation model is difficult to maintain in the long run. 
(3) In the incomplete information Cournot model, if set $c_{1}^{L}=c_{1}^{H}=\mathrm{c}_{1}$, for banks and third-party payment service providers, the cost of mobile operators is certain, so the Cournot model with incomplete information is equivalent to the complete information. Compare the Nash equilibriums $q_{1}^{L}, q_{1}^{H}, q_{2}, q_{3}$ in the incomplete information Cournot model with the

Nash equilibriums $q_{1}=\frac{a+c_{2}+\mathrm{c}_{3}-3 \mathrm{c}_{1}}{4 b} q_{2}=\frac{a+c_{1}+\mathrm{c}_{3}-3 \mathrm{c}_{2}}{4 b}, q_{3}=\frac{a+c_{1}+\mathrm{c}_{2}-3 \mathrm{c}_{3}}{4 b}$ :

When $c_{1}=c_{1}^{L}, \quad q_{1}^{H}=\frac{a+c_{3}+c_{2}-(3-\theta) c_{1}^{L}-\theta c_{1}^{H}}{4 b}<q_{1}=\frac{a+c_{2}+\mathrm{c}_{3}-3 \mathrm{c}_{1}}{4 b}$.

When $c_{1}=c_{1}^{H}, \quad q_{1}^{L}=\frac{a+c_{3}+c_{2}-(1-\theta) c_{1}^{L}-(2+\theta) c_{1}^{H}}{4 b}>q_{1}=\frac{a+c_{2}+\mathrm{c}_{3}-3 \mathrm{c}_{1}}{4 b}$.

The difference in the results above can mainly be attributed to the mobile operator. When making decisions, mobile operators should not only adjust the business volume of mobile payment service based on their costs, but also be aware that banks and third-party payment service providers are not clear about their costs. When the mobile operator's costs are high, it should reduce its business volume of mobile payment services. But considering that banks and third-party payment service providers are not aware of the high costs of mobile operators, so the volume of services what they provided will lower than knowing the costs. Therefore, at this point, mobile operators can increase their volume of mobile payment services.

\section{Conclusion}

By comparing and analyzing the complete information Cournot Model, incomplete information Cournot Model, as well as the collaboration model, we can learn that in the mobile payment market, if mobile operators, banks and third-party payment service providers only pursuing their own interests for their own benefits, the trilateral game will inevitably fall into the "prisoner's dilemma", where the production suffers low efficiency, enormous waste of resources and higher cost, thus it will lead to the loss of social welfare. The participants in the mobile payment market should adopt a cooperative strategy to improve the overall interests for all parties, thus the possible market development dilemma caused by not-cooperation can be avoided. Taking China's current situation into consideration, we analyze the main types of mobile payment operation models. The first one is the mobile operator-oriented model. Operators have the advantage of being closed to mobile phone users, however, mobile operators only are able to proceed micro payments. Because the high value payment proceeding by the mobile operator will result in a large amount of fund precipitation, which is against the country's financial policy, thus will limit the development of mobile payment services. The second model is the bank-oriented model. Banks have the advantage of being closed to bank card users, but mobile payment services are not able to proceed cross different banks, each bank can only provide services to their own users. Also the banks need to maintain and upgrade their payment systems, which will inevitably require huge cost, thus will limit the extension of bank mobile payment services. The third model is the third-party payment platform-oriented model. As the bridge between the mobile operators and commercial banks, the third-party payment platform embraces the advantages of being closed to e-commerce users, and plays a coordinating role to integrate resources to operate effectively on their own payment platform. Meanwhile, the third-party payment platform-oriented model will require stronger coordination, funding, market capacity and technical ability from third-party payment service providers. If the third-party payment service provider fails to meet the requirements, it may lead the entire mobile payment 
industrial chain to a paralysis situation. In summary, from the perspectives of mobile operators, banks, and third-party payment service providers, we establish the complete information Cournot Model and incomplete information Cournot Model, and through analyzing the game models, we presented the outcome of equilibrium and proposed the operation model for China's own mobile payment market, which will be based on the joint collaboration of mobile operators and banks, with the support by third-party service providers. Mobile operators and banks collaborate through the establishment of alliances relation, to cooperatively control the whole industry chain, especially in the field of information security, product development and resource sharing. The third-party payment service provider will take full advantage of its technical ability, marketing ability, fund operation ability and business innovation ability to support mobile operators and banks. Through collaboration, these three participants will enjoy resources sharing, complement each other's advantages and finally improve the efficiency of the value chain. In this study, the models did not take some complex factors into account, which still need to be further modify and analysis in order to provide better models and solutions for our country's mobile payment market, thus to accelerate the market development and build a healthy mobile payment market for China.

\section{References}

[1] Mobile Payments [EB/OL]. http://en.wikipedia.org/wiki/Mobile_payments.

[2] Z. Anwei and W. Jun, "The analysis of Dominant force in the mobile payment industry based on chain Perspective", J. Economic perspective, vol. 9, (2003).

[3] H. Rongzhi, "Distribution of benefits is the key to the success of mobile payments", J. Mobile Communications, vol. 11, no. 33, (2009).

[4] J. Yong, "The study of mobile payment industry chain in china based on game theory analysis", D, Beijing University of Posts and Telecommunications, (2008).

[5] Z. Huifeng, "The challenges and opportunities of Mobile Payments which telecommunications operators as leader", J, Mobile Communications, vol. 11, no. 33, (2009).

[6] M. Fengchao and S. Ying, "Mobile payment: the dominant mode of operators is mainstream", J, World Telecommunication, vol. 11, no. 20, (2007).

[7] H. Jun, "Research of the operation models for mobile payment industry in china", D, Beijing University of Posts and Telecommunications, (2009).

[8] G. Haiying, Z. Yunhua and Z. Zhenhua, "The analysis of industrial chain patterns and profit model calculation of mobile payment", J, Shanghai Finance, vol. 9, (2011).

[9] Z. Chunyan, "Research on Business Model of China's Mobile Payment", D, Dongbei university of Finance and Economics, (2011).

[10] W. Guoqiang, "Research on Payment Mode of Mobile E-Commerce Dominated by Mobile Operators", D, Chongqing University, (2012).

[11] C. Yuebo, "Research on Internet banking relationship with third party payment", J. Zhejiang Finance, vol. 6, (2008).

[12] Z. Xisong, "The Choice of the Development Models of Chinese Third Party Payments in the View of the Commercial Banks", Journal of Xi An University of Finance and Economics, vol. 2, no. 22, (2009).

[13] L. Lei, Y. Xingli and L. Tingjie, "Game Between Mobile Operators and Bankcard Associations in Mobile Payment Market”, Journal of Xidian University (Social Science Edition), vol. 4, no. 18, (2008).

[14] W. Wenzhong, "Shaping the new generation of electronic payments by mobile banking", J, Financial Electronization, vol. 10, (2009).

[15] Z. Wei, "Mobile Payment and Management Research in the E-Commerce of the3G era", D, Beijing University of Posts and Telecommunications, (2009).

[16] G. Hongye, Editor, "Microeconomics", RenMin University of china Press, Beijing, (2007).

[17] Z. Weiying, Editor, "Game Theory and Information Economics", Shanghai Renmin Press, Shanghai, vol. 1, (2004), pp. 39-42. 


\section{Authors}

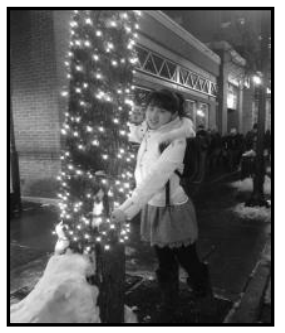

Miao Miao, is a lecturer in School of Economics and Management at Southwest Jiaotong University, she received her Ph.D. from Southwest Jiaotong University (2007) and received her M.A. from Beijing University of Science and Technology (2004). Her current research interests include E-Commerce, mobile payment and mobile number portability.

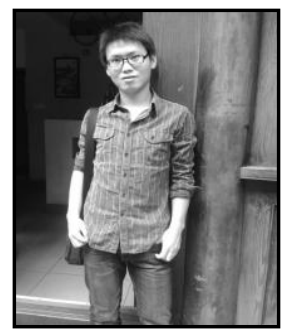

Fangping Xiong, $\mathrm{He}$ is a Master Candidate of Southwest Jiaotong University, his Research Interests include E-Commerce and mobile payment.

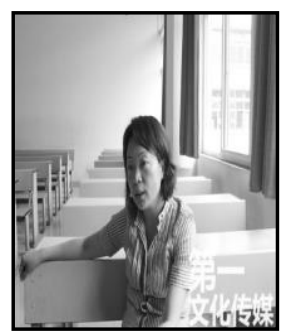

Jing Zhou, is an associate professor in School of Economics and Management at Southwest Jiaotong University, she received her Ph.D. from Southwest Jiaotong University and received her M.A. from the same place. Her current research interests include E-Commerce and Marketing. 